\title{
Cartografia de um grupo-pensamento em saúde mental: experimentaçôes rizomáticas no que a vida pode mais
}

I 1 Ana Karenina de Melo Arraes Amorim, ${ }^{2}$ Ana Kalliny de Sousa Severo,

${ }^{3}$ Roberta Carvalho Romagnol I

Resumo: Este artigo trata da experiência de um grupo composto por usuários e trabalhadores de serviços de saúde mental de Natal (RN), estudantes de cursos de graduação em saúde e professores e pesquisadores da área interessados na discussão de temas e experiências em saúde mental. Fundamentados na esquizoanálise e seu método cartográfico, argumentamos que o grupo funciona como grupo-pensamento ao constituir espaço de produção de pensamento imanente à vida, através de um funcionamento rizomático. Para tanto, a cartografia foi traçada em três linhas de composição, construídas com base em notas de diário de bordo das autoras. São elas: 1) Tensões entre a legitimidade da Universidade como lugar-veículo da verdade do pensamento e a construção de um grupo-pensamento;

2) Novas maneiras de experimentar a crise: o "dia da festa" e o grupo com as funções de suporte e cuidado; e 3) A tessitura de novos modos de existir: das exigências por um grupo homogêneo à deflagração de movimentos heterogêneos. Esperamos com essa cartografia contribuir para a produção de novas práticas em saúde mental que insistam na potência da loucura e dos encontros na invenção da vida.

> Palavras-chave: Saúde mental; grupalidade; esquizoanálise; cartografia; análise institucional.
1 Universidade Federal do Rio Grande do Norte, Psicologia. Natal-RN, Brasil. Endereço eletrônico: akarraes@gmail.com

${ }^{2}$ Universidade Potiguar. NatalRN, Brasil. Endereço eletrônico: akssevero@gmail.com

${ }^{3}$ Pontifícia Universidade Católica de Minas Gerais, Psicologia. Belo Horizonte-MG, Brasil. Endereço eletrônico: robertaroma@uol.com.br

Recebido em: 22/09/2014 Aprovado em: 07/02/2015 


\section{Introdução}

No campo da saúde mental é frequente o trabalho com oficinas e grupos terapêuticos, grupos de ajuda e suporte mútuos, entre outros dispositivos grupais que participam dos processos de desinstitucionalização e reinserção social de pessoas com transtornos mentais em geral e de seus familiares e cuidadores. Essas grupalidades ganham diferentes formas e parecem ter em comum o fato de que estão a serviço da produção de saúde mental dos seus atores e se utilizam de tecnologias do campo da Psicologia, da Psicanálise, das Ciências Sociais e das Artes, dentre outras. No entanto, usualmente, esses dispositivos se encerram no interior dos serviços de saúde mental ou estão a eles fortemente vinculados pela participação de profissionais e usuários do mesmo serviço ou território de referência.

Estudos têm mostrado como há importantes processos de institucionalização dos Centros de Atenção Psicossocial (CAPS) e outros dispositivos de atenção em saúde mental, que perdem sua potência desinstitucionalizante e se burocratizam. Barros (2003) sinalizou para o risco da institucionalização-cronificação dos CAPS. Na realidade da cidade de Natal (RN), observamos que usuários estão dependentes dos CAPS e têm sua vida restrita ao circuito CAPS-residência na maior parte de suas vidas (LEÃO; SEVERO; DIMENSTEIN, 2009; BRITO et. al, 2009). Em diferentes contextos, isso se relaciona às novas cronicidades produzidas, que envolvem usuários, modos de gestão, dispositivos e profissionais, e às cronicidades geradas pela inexistência ou fragilidade das redes de atenção (BARROS, 2003; AMORIM; DIMENSTEIN, 2009). Pande e Amarante (2011) também constatam essa cronificação e a importância de os técnicos e gestores reconhecerem os riscos da institucionalização e operarem críticas, além de se produzir movimentos para além das atividades centradas nos serviços.

Assim, na tentativa de romper com essa lógica e produzir outros movimentos, apresentamos uma cartografia da atualidade de um coletivo, um "grupopensamento" que tem sido produzido nos encontros entre pessoas, em seus devires e também em suas capturas identitárias enquanto acadêmicos, trabalhadores, cidadãos, portadores de transtornos mentais, psicólogos, entre outros interessados em discutir juntos temáticas e problemas no campo da saúde mental e da reforma psiquiátrica na cidade de Natal. 
A partir da cartografia e de algumas referências da esquizoanálise e da análise institucional, é possível discutir o movimento desse coletivo como espaço de pensamento e de produção de novas formas de vida das pessoas envolvidas e, com ela, novos protagonismos no campo social e político da saúde mental. Vale lembrar que a esquizoanálise e a análise institucional são correntes que fazem parte do movimento institucionalista em nosso país. Ao analisar a história desse movimento no Brasil, em um estudo histórico-genealógico, Rodrigues (1999) localiza sua implantação por argentinos, nos últimos anos da década de 1970, tendo como área inicial de atuação a saúde mental, defendendo uma prática grupalista, com articulação interdisciplinar e associada a setores populares. Já na década de 1980, a partir de trabalhos teóricos e de intervenção, firmam-se as abordagens da análise institucional, também chamada socioanálise, de René Lourau e Georges Lapassade, e da esquizoanálise de Gilles Deleuze e Félix Guattari. Esse processo foi marcado por um intenso diálogo crítico com diversos campos de saber, em diferentes campos teórico-práticos com características instituintes, caracterizando-se como um movimento plural marcado por um conjunto de afinidades e diferenças.

\section{Configurações do grupo}

Em 2010, ocorreu a IV Conferência Nacional de Saúde Mental (CNSM). Um dos importantes eixos de debate foi o fortalecimento dos movimentos sociais, demonstrando claramente a necessidade da inclusão dos vários atores no processo da Reforma Psiquiátrica. Além disso, a ideia da intersetorialidade "[...] foi um avanço radical em relação às conferências anteriores e atendeu às exigências reais e concretas que a mudança do modelo de atenção trouxe para todos" (BRASIL, 2010, p. 7). Houve grande participação de trabalhadores, usuários e gestores da saúde e de outros setores (aproximadamente 46 mil pessoas nas três etapas).

$\mathrm{Na}$ esteira desse movimento nacional e no contexto sociopolítico local, o grupo iniciou a partir do desejo de um grupo de usuários e técnicos de um CAPS de montar uma associação e da nossa proposição, como pesquisadoras e militantes, de acompanhar esse processo de construção. A partir desse acompanhamento, foi possível produzir um coletivo do qual participamos ativamente e que produziu diferentes grupalidades, passou por transformações mais ou menos potentes 
para as vidas em jogo e para o campo da saúde mental na cidade. A noção de coletivo é aqui entendida como "plano de coengendramento dos indivíduos e da sociedade", espaço de criação que supera a dicotomia indivíduo-sociedade e desnaturaliza esses termos (ESCÓSSIA; KASTRUP, 2005, p. 303).

Em 2011, o grupo experimentou uma proposta de funcionar como grupo de suporte mútuo, com a participação de estagiários do curso de graduação em Psicologia. No entanto, após o final do estágio, o grupo se dispersou e, ao longo de 2012 e início de 2013, esteve praticamente sem funcionar. Os participantes encontravam-se pontualmente e não mantiveram o espaço coletivo como antes.

Ao longo do primeiro semestre de 2013, houve uma reaproximação dos participantes, formando uma nova grupalidade. Nesse momento, o convite foi feito para que os usuários e trabalhadores pudessem participar dos encontros, que tinham por objetivo pensar e compartilhar ideias acerca da inserção dos usuários de saúde mental em iniciativas culturais da cidade, tendo como ponto de partida os dados produzidos em uma pesquisa coordenada pela primeira autora e a partir das experiências dos diversos participantes. No segundo semestre de 2013, o desejo de encontrar-se e fortalecer-se enquanto grupo ultrapassou os limites do tempo formal proposto inicialmente, possibilitando assim outros desenhos relativos à discussão e ao seu funcionamento. Desde o início do ano de 2014, esse grupo está registrado formalmente como projeto de extensão universitária, aberto à comunidade acadêmica e às pessoas da comunidade em geral.

Os encontros têm acontecido semanalmente e são movidos pelo interesse nesse campo específico e em suas possíveis transformações com implicações na vida de cada um, mas também pelo encontro em si, pelas potências e intensidades afetivas que ali são ativadas. Nesses encontros, o grupo ganha novas formas a cada vez em função dos participantes, de suas necessidades e seus projetos. Como é aberto, há aqueles que participam sempre, outros que têm participação menos regular e há visitantes que experimentam o grupo uma vez e não seguem.

No intuito de convocar a transdiciplinaridade e a heterogeneidade, dentre os participantes estão estudantes de graduação e pós-graduação em Psicologia, enfermagem, gestão de sistemas de saúde, entre outras; usuários da rede de saúde mental municipal; pesquisadores e professores de cursos de Psicologia da cidade; 
trabalhadores das redes de saúde da região metropolitana da cidade e, eventualmente, gestores locais, quando convidados a debater algum tema específico.

Assim, com participações variadas, circulam crenças, valores, reproduções dos lugares instituídos, das tutelas sustentadas nas hierarquias de poder-saber, mas também há aberturas à conexão e às possibilidades de experimentar e inventar outros modos de subjetivacão. Desse modo, "[...] todo conhecimento se produz em um campo de implicações cruzadas, estando necessariamente determinado neste jogo de forças: valores, interesses, expectativas, compromissos, desejos, crenças, etc" (PASSOS; BARROS, 2010a, p. 19). É esse jogo, terreno de implicações, que constitui a matéria mesma dos encontros, que não se situam em um campo de intervenções em cujas finalidades se reconhece como "da clínica", "da política" ou "da pesquisa", mas numa transversalidade, no sentido dado por Guattari (2004). Na transversalidade, conectam-se elementos diversos, conceitos e campos distintos, sustentando-se a complexidade e a produção. Nessa experimentação, o grupo foi se compondo espaço de pesquisa-intervenção cartográfica, plano de experimentação que pode ser cartografado em seus efeitos-processos clínicos, políticos e epistêmicos.

As experimentações no grupo aqui discutidas foram registradas por duas das autoras em pequenas notas, textos escritos no calor dos encontros e registros fotográficos, que compuseram diários pouco estruturados, mais ou menos completos, do que viveram ao longo dos anos de 2013 e 2014. Assim, atendendo às exigências de uma política de narratividade na pesquisa-intervenção cartográfica, construímos diários de bordo, tal como proposto por Passos e Barros (2010b). A escrita dos diários não respeitou a cronologia dos encontros, mas o movimento intensivo da necessidade de escrever, de viver a memória do vivido na escrita e, em alguns momentos, também na fotografia. A intensidade dos encontros, ou do encontro das potências que ali se afirmavam, convocou em nós a escrita como acontecimento. Acontecimento no sentido foucaultiano, que desconstrói a ideia de história como narrativa reprodutiva da verdade dos fatos e reconhece os regimes de verdade que se apresentam nas descontinuidades, nas rupturas, nas fissuras do presente. Para Foucault (1981), acontecimento é "uma relação de forças que se inverte, um poder confiscado, um vocábulo retomado e voltado 
contra seus utilizadores, uma dominação que se enfraquece, se distende, se envenena e uma outra que faz sua entrada, mascarada" (p. 28).

$\mathrm{O}$ acontecimento, sem compromisso com a descrição dos fatos, mapeia as rupturas, os desvios, as surpresas e os afetos a cada vez. Assim, os diários contemplaram

\begin{abstract}
a espessura temporal dos devaneios do pesquisador (...). O pesquisador produz um corpo de dados que transversaliza memória, história e presente e o devir-pesquisador produz ressonâncias entre o inusitado e o atemporal. (...) Assumimos, aqui, a impossibilidade do dado "bruto", da experiência "por si só" e sim a possibilidade da escrita e da experimentação enquanto simulacros. (MOLIN, 2011, p.306)
\end{abstract}

Com base nesses diários de bordo e inspiradas pelas ideias de Deleuze e Guattari, realizamos a cartografia, que apreende a complexidade, coloca problemas, rastreia o plano de forças que compõe a realidade, na maioria das vezes em favor da reprodução, mas que outras vezes opera também em favor de agenciamentos produtivos. Como destaca Romagnoli (2009), ela busca desarticular as práticas e os discursos instituídos, bem como as relaçôes despotencializadoras que impedem a invenção, acreditando que é nesse jogo que se dá a construção do conhecimento. Fizemos a cartografia trabalhando numa política avessa ao império da representação/interpretação e que se coloca em ato numa sustentação do potencial ativo do pensamento no real vivido.

Para tanto, tomamos os princípios do rizoma como imagem do pensamento em Deleuze e Guattari (1995) para ir indicando o grupo como grupo-pensamento e problematizando as implicações em jogo e as linhas de produção das subjetividades. Resolvemos problematizar a experiência considerando transversalmente duas perguntas éticas fundamentais em seus desdobramentos: 1) "O que pode um corpo?" ou "O que pode a vida, o que mais pode a vida?”, como pergunta Deleuze (1997) baseado nas ideias de Espinosa; e 2) "Como ser digno do que nos acontece?”, outra pergunta deleuziana, dessa vez inspirada em Nietzsche (DELEUZE, 2003). As perguntas guardam o fundamento ético e político de que a vida pode e que precisa sempre ser inventada no e para o presente; vida que cria mundos. $\mathrm{O}$ trabalho do grupo aqui apresentado insiste nesse fundamento, resistindo às forças de captura e opressão a que estamos sujeitos em nossas delimitaçõos institucionais, ideias estabelecidas e regimes de verdade. 


\section{Rizoma e antigenealogia na produção do grupo}

Deleuze e Guattari (1995) criticam as categorias do pensamento ocidental e propóem uma nova imagem do pensamento e do mundo: o rizoma. Essa imagem do pensamento se opõe à ideia de transcendência defendida por Platão, na qual o pensamento se liga a um modelo a partir do qual se buscam semelhanças. Pensar por transcendência implica em um modo hierárquico e estratificado de conhecer, em que o mundo das ideias é separado do mundo do sensível. De acordo com Fuganti (1990), essa divisão funda o primado da representação na filosofia ocidental e opera um corte entre o desejo e o pensamento, no qual as essências, as ideias, são valores supremos que existem separados dos corpos sensíveis. Pensar não significa produzir uma realidade nova, pois o valor da verdade só pode ser atribuído a um conhecimento que reproduza por semelhança as relações internas ao modo inteligível e imutável. Dessa maneira, viver seria buscar a verdade, contida nas ideias, cujos modelos funcionam em prol de uma ordem universal transcendente.

Frente a essa forma dominante de pensar, Schopke (2004) nos lembra que a leitura deleuziana propóe um pensamento que dribla a representação e aposta na invenção, abandonando o domínio da representação e entrando no domínio da experimentação, dos agenciamentos, dos fluxos, de um mundo que se compõe e decompõe pelas relações. Nessa perspectiva, pensar é experimentar, a experimentação define o que é pensar e resulta da tensão das linhas da realidade (GODINHO, 2007).

Deleuze e Guattari (1995) propóem o rizoma como uma imagem do pensamento, tomando a Psicanálise e a Linguística como referências importantes da crítica que operam, ou seja, os desvios que operam em relação a essas disciplinas de pensamento. O rizoma é um conceito botânico que indica uma diferença em relação à raiz fasciculada ou tubérculo, consistindo numa espécie de raiz com passagens subterrâneas, sem uma centralidade ou eixo identificável. $\mathrm{O}$ pensamento rizomático seria, então, o pensamento sem começos ou fins ou centros, mas que atesta a capacidade da inteligência de encontrar começos e de se multiplicar. O rizoma é produção do inconsciente, mas um inconsciente sem subjetivação ou representação estruturante. Funciona como um labirinto no qual não há saídas ou entradas, começo ou fim, centro ou periferia, num sistema de 
atalhos e desvios. Ou seja, o pensamento funciona pelo meio e se expande por conexôes e produções de linhas mais ou menos duras, mais ou menos flexíveis e moleculares. O pensamento rizomático é também um pensamento da imanência e da superfície, e que não pretende significar, representar ou sujeitar. Assim, descentrado, da imanência do pensamento derivam suas conexões, produzindo-o necessariamente como coletivo e conectivo, feito de E, E, E, livre de hierarquias, classificações, estruturas dadas a priori. Pensamento como produção imanente do desejo que não se faz apartado do mundo sensível, da cotidianidade, da vida mesma em sua intensidade e extensão.

A partir dessa perspectiva de pensamento, tomamos os princípios do rizoma para colocar em análise esse grupo-pensamento em causa. O objetivo é que possamos trabalhar os conceitos e princípios do rizoma para produzir pensamento na imanência dessa experiência.

Um dos princípios do rizoma é o da antigenealogia. Curiosamente e não por acaso, a ideia de antigenealogia aqui em Deleuze e Guattari (1995) aproximase da ideia de genealogia em Foucault (1996), no sentido de não buscar as origens ou datas dos fatos, mas a singularidade dos acontecimentos nos pontos onde há ruptura e produção de diferença nos modos de ver e dizer, ou seja, nos modos de subjetivação em certo tempo histórico. Assim, tanto a genealogia foucaultiana, como o principio antigenealógico do pensamento rizomático em Deleuze e Guattari (1995) propóem o mapeamento do processo de produção dos acontecimentos a fim de identificar o campo de forças em jogo e o traçado das linhas na produção micropolítica dos processos de subjetivação. Aqui, Deleuze e Guattari (1995) trabalham a ideia de que não interessa a causa do pensamento ou a origem dos fatos, nem o início ou o fim de uma teoria e de uma história, mas o seu meio. O pensamento-vida brota no meio das coisas, no intermezzo, na dimensão dos encontros. Portanto, para acompanhar a vida e produzir nela, é preciso estar atento ao que se passa no meio, nos encontros possíveis. Dessa maneira, não contamos a história cronológica e descritiva do grupo, mas procuramos mapear o que foi se produzindo como acontecimento que marca e sustenta a existência desse espaço coletivo de vidas.

Anos antes de constituir-se como projeto de extensão em seu formato atual, alguns participantes do grupo começaram a encontrar-se em torno da ideia de uma associação em saúde mental. Após alguns meses de trabalho e 
encontros entre acadêmicos, pesquisadores, usuários, familiares e trabalhadores, a associação foi instituída e teve protagonismos importantes no cenário local, sobretudo no momento da IV CNSM. No entanto, no período pós-conferência, o grupo dispersou-se, o espaço instituído de encontros se desfez nas burocracias em torno da "institucionalização" de uma associação e o que ia se configurando como movimento social perdeu força.

Nesse momento de desencontros, por iniciativa de alguns usuários que queriam retomar a discussão da associação e de estagiários do curso de Psicologia, configurou-se um grupo de "suporte mútuo", no sentido proposto por Vasconcelos (2007): são pensadas iniciativas de cuidado e suporte concreto do cotidiano em atividades de lazer e cultura, como também projetos complexos "como dispositivos residenciais e de trabalho protegido e cooperativo, de cuidado domiciliar, de acompanhamento" (p. 179). Contudo, após um ano de encontros, com o final dos estágios, novamente, desfaz-se o espaço de encontros e seus participantes se dispersam, como se o grupo só pudesse se fazer institucionalmente se marcado pela tutela acadêmica.

$\mathrm{O}$ que cartografamos aí foram as linhas molares do desejo, que produziram instituições e, com elas, o protagonismo macropolítico de pessoas portadoras de transtornos mentais. Este foi se configurando em participações efetivas em instâncias do poder público, no controle social, naquilo que dizia respeito aos seus direitos, como a produção de audiências públicas e a produção de um livro por um dos usuários. De outro modo, nas linhas moleculares do desejo, também foi se dando a produção de outros modos de estar na vida, em que a identidade "usuário" ora se renovava, ora se endurecia e ora se desfazia em sentido na vida dessas pessoas e se hibridizava com outros devires, como o devir-estudante, o devir-avô, o devir-escritor, o devir-poeta, o devir-pintor, o devir-psicólogo, o devircuidador, entre outros que foram se inventando. Micropolítica dos encontros se delineando entre assujeitamentos e processos inventivos.

Cartografamos também as linhas duras das estagnações que os movimentos instituídos nas diferentes modalidades de grupo produziram. As formas de grupalidade e seus objetivos mudaram. Com elas, o espaço de produção do desejo foi sendo minado a cada vez e sua fragilidade, pode-se dizer, reforçada na tutela dos "acadêmicos", que viam na associação espaço de poder e influência junto à rede de saúde e suas direções. Fragilidade também revelada na tutela 
dos trabalhadores, que viam a associação e o grupo mais como alternativas para "desafogar" os serviços e menos como um espaço de produção de projetos singulares e novas formas de viver na cidade. Assim, o que se tinha instituído era mais um grupo que reproduzia as funções de mais uma oficina terapêutica, mais uma reunião, mais uma assembleia, mais um espaço de ocupação do tempo ocioso dos usuários, como nos foi dito algumas vezes pelos mesmos. A mimese desses dispositivos ia tirando a força do campo de invenção, e as diferenças também desapareciam, de tal modo que a participação no grupo foi sendo acompanhada de menor participação nos demais dispositivos (tais como oficinas, cursos, escrita, dentre outros) e não em sua problematização e uso na produção de novas formas de viver. Esses diferentes dispositivos reproduziam-se por força das necessidades dos usuários de terem lugar para falar "fora do CAPS" e das necessidades dos "acadêmicos" de poder "falar do CAPS de fora", sem que isso desse lugar à transformação das relações já instituídas e à construção de projetos concretos de vida. Então, entre as conexões vividas, alguns fluxos passaram e produziram os deslocamentos e outros estancaram, de tal modo que novamente houve dispersão e enfraquecimento do espaço de encontro.

Outro elemento a ser analisado nesta antigenealogia do grupo é que a forma como se configurava respondia sempre a uma lógica determinada e estabelecida $a$ priori do que tinha que se produzir nos encontros: ora o fomento a uma associação que deveria ter projetos de geração de renda, entre outros, que garantiriam a existência da associação, ora a produção de projetos que teriam início e fim com o tempo da instituição estágio ou da pesquisa universitária, sem que o próprio grupo tivesse conseguido sustentar alternativas de continuidade não dependentes da universidade. Ao reconhecer isso, vislumbramos a possibilidade dos encontros "circularem" dentro e fora da universidade e da rede de saúde, o que foi conferindo ao grupo outro movimento. Nesse momento, outros princípios rizomáticos puderam ser experimentados. Esse funcionamento rizomático também foi percebido por Santos e Romagnoli (2012), dos efeitos para além da Academia, ao efetuarem uma pesquisa-intervenção através de oficinas de teatro em um serviço substitutivo de Belo Horizonte. As autoras também enfatizaram a potência do coletivo e a importância desses processos para a desinstitucionalização da loucura. 


\section{Multiplicidade e ruptura a-significante na atualidade do grupo-pensamento}

Após quase um ano sem reuniōes efetivas, por ocasião do encontro de duas das autoras em um trabalho de pesquisa sobre saúde mental e cultura, e nutridas pelo desejo de produzir espaços de diálogo horizontais entre atores da universidade e da rede de saúde mental, pensamos em retomá-las e convidamos os antigos participantes. Nem todos compareceram; os que vieram trouxeram outros, todos interessados em saúde mental e luta antimanicomial.

Assim, pelo desejo mesmo de estar ali, analisamos o que produziu a ruptura, os desencontros e a nossa dispersão, e, dentre outras coisas, pensamos que precisávamos deixar as coisas mais "em aberto" e ir experimentando o desejo de estar juntos. Alguns propuseram a itinerância do grupo, que não foi totalmente aceita pela dificuldade de alguns em se deslocar na cidade. Mas, mesmo com um local de encontro certo, resolvemos aos poucos circular dentro e fora da universidade e da rede de saúde, sem "quartel general". Nesse sentido,

[t] odo rizoma compreende linhas de segmentaridade segundo as quais ele é estratificado, territorializado, organizado, significado, atribuído, etc; mas compreende também linhas de desterritorialização pelas quais ele foge sem parar. Há ruptura no rizoma cada vez que linhas de segmentaridade explodem em linhas de fuga, mas a linha de fuga faz parte do rizoma. Essas linhas não param de se remeter umas às outras. É por isso que não se pode contar com um dualismo ou uma dicotomia [...]. Os grupos e os indivíduos contêm microfascismos sempre à espera de cristalização. (DELEUZE; GUATTARI, 1995, p. 18)

Assim, atentos aos microfascismos e também às possibilidades de desterritorialização, resolvemos buscar outros territórios geográficos como se fossem catalisadores na produção de outros territórios existenciais do grupo em experimentação, na tentativa de ativar o nomadismo em contraposição ao sedentarismo. Em sua configuração mais atual, o grupo circula por outros espaços da cidade, e os encontros acontecem na rede de saúde, na universidade, mas também em nossas casas, na livraria, no restaurante, no parque, na praça, movido pelo desejo que emerge a cada encontro e dos temas e objetivos que vamos traçando, orientados pelas necessárias "linhas de segmentaridade" que nos organizam. Tentamos nos agarrar à instituição "cronograma de discussão 
de temas", mas também isso foi se desfazendo, de modo que as nossas leituras e discussões também vão se dando de modo rizomático, conectando os textos que elegemos, as nossas "urgências de conversa", dado aquilo que acontece em nossas vidas e queremos partilhar, as presenças de pessoas diferentes que aparecem ou convidamos, e também os diferentes modos de pensar e ver o mundo que se apresentam. Recebemos a coordenação de saúde mental do município, professores de outras regiōes que estudam saúde mental e usuários que estão fora da cidade e, quando retornam, vêm nos visitar. A multiplicidade se faz presente nos diferentes modos de funcionar do grupo a cada encontro. Esse modo mais fluido de ir construindo os encontros parece convidar a estar ali porque a função "coordenador" foi se diluindo, ainda que, vez ou outra, um dos pesquisadores tome a função de continente e conduza os encontros de modo a viabilizá-los no tempo da manhã que elegemos para acontecer.

No desejo de produção de mundo, de outros mundos, está a linha que contorna e que abre, ora dura, ora flexível, de produção de novas formas de viver em sociedade com a loucura. Para tanto, o exercício do pensamento tem lugar fundamental. No sentido proposto por Deleuze e Guattari (1995), pensamento é vida. Esses autores procuram descolá-lo da imagem do pensamento excludente, totalizado nas ideias de "razão" e "representação", entendido como fruto da razão sedentária, que repete e não inventa. Propõem outra imagem do pensamento, como processo que tende ao infinito e que é diferente de recognição como uma função psicológica. $\mathrm{O}$ pensamento diz respeito à qualidade de produzir conexōes que potencializem a vida em sua singularidade, que potencializem modos de viver capazes de produzir mais vida para além das práticas sociais vigentes, na imanência da própria vida (SCHOPKE, 2004). Assim, o pensamento-vida em Deleuze e Guattari (1995) vai além da subjetividade, envolvendo as dimensões metalinguística, afetiva, material e imaterial.

O grupo que cartografamos constitui-se como grupo-pensamento quando se faz espaço em que outros modos de pensar são possíveis, produzindo outros modos de viver, ativando as vidas, bem como "sobras" não subjetivas no campo das intensidades. Ali têm lugar as diferentes formas de dizer que traduzem em alguma medida as diferentes formas de pensar e viver, sem que sejam reduzidas a "sintoma" desta ou daquela condição subjetiva. Entram na cena do grupo os 
pensamentos por assonância, em suas conexões sonoras, assim como os furos e sopros expressivos dos "sem sentido" manifestando as intensidades afetivas. Assim, no grupo, no meio de uma conversa sobre a dificuldade do trânsito que nos estressava antes de chegar no encontro, emerge no grupo uma conexão sonora entre as palavras "gentileza" (em sua ausência nas experiências do trânsito) e "gente lesa" (as pessoas que assim se revelam violentas ou desrespeitosas) e há a acolhida dos "estressados" da ocasião. E as sonoridades assim se fazem, solidárias as experiências do cotidiano.

O movimento se dá pela análise desses momentos e demandas explicitadas, ativadas pelas próprias diferenças presentes, que produzem intercessões e furam as reproduções. Desenvolve-se, então, uma intensiva "atenção à espreita”, que garante a emergência da diferença. $\mathrm{O}$ exercício da atenção, como propôs Kastrup (2007), envolve a ativação de uma atenção flutuante, concentrada e aberta, com a inibição da atenção seletiva, que habitualmente domina nosso funcionamento cognitivo, evitando os dois extremos da atenção, quais sejam, a passividade relaxada ou a rigidez controlada e focalizada.

Assim, "atentos", fomos mapeando os acontecimentos, ou seja, rastreando os momentos dos quais emergiam as singularidades, as rupturas e os desvios que conduziam à invenção de novos movimentos no grupo, bem como as capturas que paralisavam o grupo.

\section{Acontecimentos e heterogênese entre os devires e as prisôes identitárias}

Seguem alguns dos acontecimentos que compuseram a heterogênese do grupo. Heterogênese no sentido da produção do grupo em suas diferentes entradas, formas de produção e sustentação das diferenças que o compõem. Indicamos esses acontecimentos a partir de linhas de análise que compóem a cartografia do grupo em sua tessitura cotidiana, com base nos registros dos nossos diários de bordo. Os relatos abordam as experiências pessoais e profissionais das autoras (como profissionais da Psicologia e docentes) em um grupo de extensão. Os acontecimentos serão relatados e analisados de modo a não identificar os participantes do grupo, preservando as normas éticas em vigor e mantendo o sigilo das colocações dos participantes. 

como lugar-veículo da verdade do pensamento e a construção de um grupo-pensamento

Propusemos encontros em que pensamentos fossem produzidos a partir da experimentação, do que ganha forma nos agenciamentos, que se "organizam" por si mesmos, modificando e conectando-nos, deixando transitar intensidades e acontecimentos imprevistos. Isso muitas vezes era difícil de conseguir, por diversos atravessamentos.

Ser vistos como docentes pelo grupo e assumir a proposição inicial gerava, por vezes, diversas tensões. $\mathrm{O}$ confronto de saberes se coloca na experiência, e a roda se abre para as discussōes sobre o que é a arte experimentada nas vidas ali presentes e a "arte dos livros", em que os professores do grupo são convocados a opinar e discutir. No entanto, em muitos momentos, a fixidez do lugar de professor se desfaz, e a ausência de opinião, de escritos e de livros tem lugar, abrindo espaço para os "não professores" dizerem seus saberes.

Em um dos momentos vivenciados, durante uma das visitas realizadas pelo grupo em um serviço substitutivo. Em meio a um grande círculo, se discutia sobre a sobre experiência de produzir poesias e músicas e como cada um poderia fazer isso. No entanto, percebíamos uma inquietação por parte de um dos participantes que sempre dirigia o olhar para onde nós, eu e outro participante, também professor, estávamos. Ao mesmo tempo em que existiam questionamentos e interrogações sobre o que era arte, buscava-se uma resposta absoluta sobre a relação arte e saúde mental ao mencionar-se que o livro que estava na mão do professor poderia fornecer uma descrição sobre arte. No entanto, diante do não fornecimento de tal definição e impulsionados pela busca de uma resposta, o grupo passa a refletir e compartilhar sobre a relação arte e vida de acordo com a experiência singular de cada um. (Diário de bordo, abril de 2014).

Nesse e em outros momentos, percebemos que o grupo se torna assujeitado, como diria Guatarri (2004), sujeita-se e prende-se ao dito dos livros e suas máximas militantes em seus devires molares. Há as linhas duras que envolvem os desejos de diagnóstico de uns, os desejos de normalização e medicalização da vida de outros e todos. Momentos em que o grupo sucumbe às exigências de estabilização e cristalização dos papéis e "o usuário" pede diagnósticos ou prescrições ao "psicólogo", à “doutora-psicóloga-professora”. Nessas circunstâncias, os movimentos se paralisam nas hierarquias de saber e poder que se reproduzem. Capturas identitárias da vida entram em cena. 
Diante de situações como essas, pensamos que a produção de grupopensamento constitui um desafio, pois, para isso, o lugar do saber da universidade na relação com os demais sujeitos da rede precisa ser constantemente analisado e revisto. Analisar as implicações que se apresentam para sair do lugar cristalizado de quem tem a resposta, de quem representa "o cuidador", para produzir análises e viver as conexões que o grupo, de fato, oferecia. As linhas duras iam se desfazendo em alguns momentos, dando lugar às linhas flexíveis de produção e reinvenção de pensamento.

Assim, com a heterogeneidade presente no grupo, podem-se experimentar momentos coletivos como grupo sujeito, ao conduzir à recusa de respostas préestabelecidas. Um dos momentos vivenciados pode ser destacado como o "dia da festa", como denominado por outro participante.

\section{Linha 2 - Novas maneiras de experimentar a crise: o "dia da festa" e o grupo com as funções de suporte e cuidado}

Outra linha deste mapa que cartografamos diz respeito às nossas relações com os excessos que se produzem dentro e fora do grupo, e que entram no seu funcionamento a cada encontro. Excessos que podem ou não estar relacionados com os adoecimentos dos participantes e entendidos ou não como crises psiquiátricas, tais como os excessos de fala (desejo de falar que transborda!), excessos de risos, excessos de movimento num dia agitado, excessos de irritabilidade pelas frustrações cotidianas, entre outros. Quando coincidem com as crises psiquiátricas e configuram excessos de mal estar, vemos a produção de formas de agir cuidadoras capazes de suportar e lidar com o sofrimento presente.

Em um dos encontros, quando chegamos à sala, os participantes estavam sentados em torno da mesa. Percebemos um olhar tenso vindo de algumas pessoas. Os estudantes estavam tentando seguir a programação com a apresentação do texto; porém, nós percebemos que um dos participantes estava muito irritado com as profissionais de um dos CAPS que ele frequentara durante aquela semana. Um mal-estar decorrente da falta de acolhimento por parte das profissionais transbordava dentro da sala em que estávamos reunidos. Mediante a tentativa de várias retomadas do assunto em pauta, o mal-estar continuava. Então diante das reclamações e inquietações do participante, começamos a falar sobre músicas e um dos estudantes começou a cantar músicas gregorianas e então, a irritação foi dando lugar à sonoridade, à música, de acordo com a preferência de cada um. Então, para acompanhar tal movimento, propusemos que fôssemos dar continuidade ao encontro em um dos parques florestais da cidade. 
Tentamos acalmá-lo conversando com ele, e ao mesmo tempo nos perguntávamos o tempo todo o que deveríamos fazer, tendo em vista a péssima relação com o CAPS instalada naquele momento. No parque florestal, caminhamos, cantamos, escrevemos, sentamos em algum lugar e o participante senta-se e escreve, silencia, emergindo daí um momento de quietude, de calma, e ele parece ter encontrado um meio de dar vazão a tudo o que sentia (Diário de bordo, dezembro de 2013).

Então, seguimos com a confraternização, com almoço e trocas de presentes e, ao final, outra docente e dois outros usuários conseguiram convencê-lo a ir ao outro CAPS da cidade onde estes eram atendidos. $\mathrm{O}$ que nos surpreendeu foi que em encontros posteriores - ao contrário dos relatos em que as intervenções em crises psiquiátricas são relembradas sempre como momentos de grande violência -, esse dia em que o grupo se mobilizou em função da crise de um dos participantes foi mencionado como "o dia da festa”. (Diário de bordo, março de 2014).

A partir desse momento, conseguimos experimentar modos coletivos de agenciar a crise, recusando a instituição Psiquiatria, marcados pela recusa de modos pré-estabelecidos de lidar com a loucura e dando lugar a um movimento instituinte de trocas e solidariedades. Compartilharam-se as angústias, os medos, mas também a força que se estabelece na invenção coletiva de intervenções que olhem e respeitem o sujeito que sofre e demanda cuidado. $\mathrm{O}$ movimento instituinte nega o instituído, na medida em que se contrapõe ao conjunto de normas e valores transcendentais que estão postos e que norteiam as práticas sociais, trazendo, também, o novo (LOURAU, 1975).

Nesse momento, percebemos que o grupo pode experimentar-se como gruposujeito, no sentido proposto por Guattari (2004) ao reconhecer a dimensão analítica e política do grupo, atento às suas próprias sujeições:

Ressalvados os períodos de sopro revolucionário, existe, ao contrário, toda práxis particular, toda química do grupo e da instituição, que é necessária para produzir "efeitos analíticos”. Seria necessário repetir, uma tal práxis não poderia ser fato a não ser de um agente coletivo - o grupo mesmo - no seu projeto de ser sujeito não somente para ele mesmo, mas também para a história. (p. 82)

Com base nessas proposições, queremos enfocar o grupo como agente coletivo que pensa suas posições, abrindo-se à diferença e aos processos criativos que nele emergem, buscando resistir às totalizações, cristalizações e unificações. $\mathrm{O}$ envolvimento efetivo dos diversos participantes do grupo e a liberdade de relacionar-se terminaram por propiciar formas de intervenção e cuidados diversos, mais horizontais, desenhando-o como um espaço de cuidado e de suporte para a 
crise "de um de nós", num movimento coletivo que assume que os excessos que nos compõem a todos.

\section{Linha 3 - A tessitura de novos modos de existir: das exigências por um grupo homogêneo à deflagração de movimentos heterogêneos}

Em diversos momentos, vivenciamos discussões acerca dos projetos dos participantes e do próprio grupo. Muitas vezes, alguns integrantes questionam sobre o grupo, sobre seu projeto, sobre projetos de vida dos usuários. Um deles, que já fora coordenador da associação de usuários que existia na cidade, é constantemente cobrado pelos demais, que afirmam que ele precisa se mobilizar e fazer pelo movimento da luta. Ele constantemente recusa esse lugar. Tal recusa do lugar instituído no grupo ocorre de diferentes maneiras, e outros lugares e projetos são buscados. Faz emergir devires, processos contínuos de mutabilidade, molecular e da ordem da conexão e das alianças. Coexistindo com as linhas duras, o devir sempre pode aflorar, mediante desestabilizaçôes dos estratos, das formas sedimentadas de relacionar (DELEUZE; GUATTARI, 1997). O deviruniversitário, o devir-alfabetizado, o devir-palestrante, o devir-mestrando, o devir-professor de pintura e futebol, o devir-usuário-estudante e a tessitura de novos projetos de vida, foram reinventados pelos diversos participantes do grupo. Em nossos diários, registramos momentos do processo de alfabetização de alguns participantes, que, ao longo do tempo, foram podendo apresentar suas primeiras experiências com as letras, lendo poesias no grupo e sendo reconhecidos por isso.

O dia em que se comemora nacionalmente o Dia da Poesia, foi especial pois alguns trouxeram e partilharam. Já há muito tempo sem vir aos nossos encontros, um dos participantes nos conta que voltou para a escola, que quer deixar de ser semianalfabeto e reclama mais uma vez do CAPS porque não consegue ser atendido como precisa. No final do grupo, esse participante pede a minha ajuda para ler uma poesia. E lê, sílaba por sílaba, no seu ritmo. Escutamos. Apresento-lhes algumas letras que esqueceu no tempo fora da escola. As sílabas são lidas e repetidas, e o participante confere aquela poesia o seu ritmo, ritmo de quem ficou muito tempo "fora". Termina a leitura orgulhoso de si e aplaudido por nós todos”. (Diário de bordo, março de 2014)

Nos encontros do grupo, pudemos nos reconhecer e ser reconhecidos em nossa potência, para além e aquém das identidades e registros instituídos do que somos, resistindo à massificação de modos de ser e, portanto, sendo porosos ao compartilhamento da vida. $\mathrm{O}$ grupo, para além das garantias de continuidade e atenção às necessidades de todos e de cada um, pode buscar seus limites como 
um grupo analítico-e-militante e aumentar seu "coeficiente de transversalidade" (GUATTARI, 2004, p. 110), segundo o qual há sempre a possibilidade de confronto com outros grupos e abertura a outros no grupo mesmo e fora dele de modo a permitir a emergência da diferença. A transversalidade do grupo reside na sua possibilidade de receber a cada vez outros movimentos e integrantes, perder outros e ir se constituindo no desejo de mundo que o impulsiona.

Recusando-nos como um grupo-sujeitado, enquanto grupo-sujeito precisamos sustentar as diferentes escolhas vivenciadas pelos participantes, resistindo a qualquer espécie de aprisionamento ou de ordens, sejam de membros internos do grupo, sejam de membros externos.

\section{Considerações finais}

No encontro passado recebi um embrulho deixado por um dos participantes. Pego o embrulho em que está um quadro grande da fotografia de duas crianças de olhar expressivo. Pergunto-lhe quem são as crianças, se eram seus filhos e por que ele havia me dado isso. Presente enigmático. Recebi a explicação de que o embrulho fora encontrado no lixo e que tinha sido de lá retirado diante de sua inquietação frente ao fato de alguém ter jogado fora as fotografias dos próprios filhos, como se fossem restos. Prometi a ele que guardaria o quadro. Então, refletimos juntos sobre a loucura como lixo na cidade (Diário de bordo, maio de 2014).

$\mathrm{Na}$ experimentação dessa grupalidade aqui apresentada em suas composições, aquilo que historicamente se exclui e vira "lixo" numa sociedade normalizadora e aprisionadora da loucura, ali pode ter lugar, é acolhido, guardado, reinventado, se expressa e se expande. Uns mais próximos da experiência do excesso e do resto, outros mais distantes; mas o incômodo é comum, traduzido ou não em desassossego que nos leva a produzir pensamento e vida.

$\mathrm{Na}$ imanência da vida, nos encontros tecidos no grupo, devires são desenhados, projetos de vida traçados, experimentaçōes de diferentes funções, diferentes formas de cuidado ganham espaço e possibilidade. Assim, a experiência aqui relatada não pretende ser modelo para nenhuma outra, mas em sua singularidade quer ser um convite à construção de novas grupalidades no campo da saúde mental, para resistir às cronicidades e aos desejos de manicômios que têm atravessado os dispositivos sanitários instituídos. Pretendemos exercitar o grupopensamento, a partir da perspectiva conectiva e não disjuntiva, possibilitando assim um exercício de reinvenção. 
Reinvenção que deve ir além da reforma de serviços, indo em direção da aposta na ousadia de buscar novos modos de cuidar, por meio da "criação de espaços de produção de relações sociais pautadas por princípios e valores que buscam reinventar a sociedade, constituindo um novo lugar para o louco" (YASUI, 2009, p. 06).

Como numa "oficina alquímica", o grupo-pensamento tem como desafio sustentar o frescor dos recomeços no fio do desejo que se reafirma a cada encontro e em que composições são inventadas fazendo acontecer a "vida entre nós”, perseguindo o norte ético de que a vida pode sempre mais na dignidade do que nos acontece ${ }^{1}$.

\section{Referências}

AMORIM, A. K. M.A.; DIMENSTEIN, M. Implicação e prudência na pesquisa em saúde mental: cartografias do Serviço Residencial Terapêutico. In: DIMENSTEIN, M. (org.) Produção do conhecimento e implicaşão no fazer pesquisa em Psicologia. Natal: EDUFRN, 2009, p. 191-218.

BARROS, R. D. R. Reforma psiquiátrica: resistências e capturas em tempos neoliberais. In: CONSELHO FEDERAL DE PSICOLOGIA (Org.). Loucura, ética e politica: escritos militantes. São Paulo: Casa do Psicólogo, 2003, p. 196-206.

BRASIL. Ministério da Saúde. IV Conferência Nacional de Saúde Mental - Intersetorial: relatório final. Brasília: Conselho Nacional de Saúde/Ministério da Saúde, 2010.

BRITO, M. et al. Desafios à Reforma Psiquiátrica: produção de vida e circulação nos espaços públicos por egressos de hospitais psiquiátricos. In: DIMENSTEIN, M. (org.). Produção do conhecimento e implicação no fazer pesquisa em Psicologia. Natal: EDUFRN, 2009, p. 51-68. DELEUZE, G. Critica e Clínica. São Paulo: Ed. 34, 1997.

. Lógica do Sentido. São Paulo: Perspectiva, 2003.

DELEUZE, G.; GUATTARI, F. Introdução: rizoma. In: . Mil Platôs: capitalismo e esquizofrenia. v. 1. Rio de Janeiro: Ed. 34. p. 11-37. 1995.

Devir-intenso, devir-animal devir-imperceptível. In: Mil Platôs: capitalismo e esquizofrenia. v. 4. São Paulo: Ed. 34. p. 11-113. 1997.

ESCÓSSIA, L.; KASTRUP, V. O conceito de coletivo como superação da dicotomia indivíduo-sociedade. Psicologia em Estudo, Maringá, v. 10, n. 2, p. 295-304, mai./ago. 2005. FOUCAULT, M. Microfisisca do Poder. 25 ed. Rio de Janeiro: Graal, 1981. . A ordem do discurso. São Paulo: Loyola, 1996. 
FUGANTI, L. A. Saúde, desejo e pensamento. Saudeloucura. São Paulo, n. 2, 1990, p. 19-82.

GODINHO, A. Linhas de estilo: estética e ontologia em Gilles Deleuze. Lisboa: Relógio D’Água, 2007.

GUATTARI, F. Psicanálise e transversalidade. Ensaios de Análise Institucional. AparecidaSP: Letras \& Ideias, 2004.

KASTRUP, V. O funcionamento da atenção no trabalho do cartógrafo. Psicologia \& Sociedade, v. 1, n. 19, p. 15-22, 2007.

LEÃO, F.; SEVERO, A. K.; DIMENSTEIN, M. O Impacto de serviços substitutivos em saúde mental na vida cotidiana de usuários e familiares. In: DIMENSTEIN, M. (org.) Produção do conhecimento e implicação no fazer pesquisa em Psicologia. Natal: EDUFRN, 2009, p. 169-190.

LOURAU, R. A Análise Institucional, Petrópolis: Vozes, 1975.

MOLIN, F. D. Rizomas e fluxos molares e moleculares da máquina-escola: confissóes de um cartógrafo. Psicologia e Sociedade. Florianópolis, v. 23, n. 2, p. 303-311, dez. 2011.

MOURA, A. H. O estabelecimento e a instituição. In: . A psicoterapia institucional e o clube dos saberes. São Paulo: Hucitec, 2003. p. 28-40.

PANDE, M. N. R.; AMARANTE, P. D. de C. Desafios para os Centros de Atenção Psicossocial como serviços substitutivos: a nova cronicidade em questão. Ciência e saúde coletiva. Rio de Janeiro, v. 16, n. 4, 2011.

PASSOS, E.; BARROS, R. B. A cartografia como método de pesquisa-intervenção. In: PASSOS, E.; KASTRUP, V.; ESCOSSIA, L. Pistas do método da cartografia: pesquisaintervenção e produção de subjetividade. Porto Alegre: Sulina, 2010a, p. 17-31.

. Diário de bordo de uma viagem-intervenção. In: PASSOS, E.; KASTRUP, V.; ESCOSSIA, L. Pistas do método da cartografia: pesquisa-intervenção e produção de subjetividade. Porto Alegre: Sulina, 2010b. p. 17-31.

RODRIGUES, H. B. C. À beira da brecha: uma história da Análise Institucional francesa nos anos 60. In: AMARANTE, P. (Org.). Ensaios: subjetividade, saúde mental, sociedade. Rio de Janeiro: Fiocruz, 2000. p. 195-256.

- Notas sobre o paradigma institucionalista: preâmbulo político-conceitual às aventuras históricas de "sócios" e "esquizos" no Rio de Janeiro. Transversões. Rio de Janeiro, v. 1, n. 1, p. 169-199, 1999.

ROMAGNOLI, R. C. A cartografia e a relação pesquisa e vida. Psicologia e Sociedade, Florianópolis, v. 21, n. 2, p. 166-173, ago. 2009.

SANTOS, N. A.; ROMAGNOLI, R. C. Quando a invenção pede passagem: ritmo e corpo nas oficinas de teatro do Centro de Referência em Saúde Mental (CERSAM) Noroeste de Belo Horizonte. Mental. Ubá, v.10, n. 18, p. 29-52. jun. 2012. 
SCHOPKE, R. Por uma filosofia da diferença: Gilles Deleuze, o pensador nômade. Rio de Janeiro: Contraponto, 2004.

VASCONCELOS, E. M. Dispositivos associativos de luta e empoderamento de usuários, familiares e trabalhadores em saúde mental no Brasil. Vivência, n. 32, p. 173-206, 2007.

YASUI, S. A atenção psicossocial e os desafios do contemporâneo: outro mundo é possível. Cadernos Brasileiros de Saúde Mental, v. 1, n. 1, p. 1-9, 2009.

\section{Nota}

${ }^{1}$ A. K. de M. A. Amorim trabalhou na concepção, projeto, análise e interpretação dos dados, redação, revisão crítica do conteúdo intelectual e aprovação da versão final do artigo. A. K. de S. Severo trabalhou na concepção, análise e interpretação dos dados, redação e revisão crítica do conteúdo intelectual do artigo, bem como na aprovação da versão final a ser publicada. R. C. Romagnoli trabalhou na concepção, redação e revisão crítica do conteúdo intelectual do artigo, bem como na aprovação da versão final a ser publicada. 
Cartography of a group-thought on mental health: rhizomatic trials in life can more This article deals with the experience of a group of users and workers in mental health services in Natal$\mathrm{RN}$, Brazil, students of undergraduate courses in health and professors and researchers from the area interested in discussing topics and experiences in mental health. Based on schizoanalysis and its cartographic method, we argue that the group functions as group-thought to be immanent space of production of thought to life through a rhizomatic operation. For both, the cartography was traced in three lines of composition built on notes logbook of the authors. They are: Line 1 - Tensions between the legitimacy of the University as a place of true vehicle of thought and building a group-thinking; Line 2 - New ways to experience the crisis: "the party day" and the group with the duties of care and support; Line 3 - The spin of new ways of exist: the requirements for a homogeneous group to trigger heterogeneous movements. We hope this cartography contributes to the production of new mental health practices that insist on the power of madness and meetings in the invention of life.

Key words: mental health; groupality; processes of subjectivity; cartography. 